\title{
Layout design of new production shop based on SLP
}

\author{
Lijie Zhao $^{1}$ \\ ${ }^{1}$ School of Economics and Management, Lanzhou University of Technology
}

\begin{abstract}
It has become the main way for heavy industry enterprises to decrease the cost to excavate "logistics resources" according to the Systematic Layout Planning (SLP). Taking the new tool shaft machining workshop of Luoyang yituo zhongcheng machinery co., LTD. as an example, through the method of field investigation and visit, we get the data of the process flow, material handling, the relationship between each process and the general situation of the new workshop. The SLP method is used to divide the work units in the workshop, analyze the relationship between logistics and non-logistics among each work unit, determine the comprehensive relationship between each operation unit, and make the position correlation diagram. Besides, we also combine the current situation of the workshop to sort out the layout scheme to reduce the production costs of the workshop.
\end{abstract}

\section{Introduction}

According to the development of heavy industry in China, the development scale of most old heavy industry companies significantly restricts their development potential due to the limitations of development factors, especially in the layout of workshops ${ }^{[1]}$. Due to the lack of perfect analysis and systematic design, the layout of production workshops of old heavy industry enterprises is mostly randomly arranged, which is not reasonable. With the development of enterprises, most factories still have not proceeded on the improvement of workshop layout. In order to solve the problem of workshop layout in heavy industry enterprises, this paper introduces the SLP method to analyze the workshop logistics and non-logistics, and plans the workshop layout to improve production efficiency ${ }^{[2-4]}$. Therefore, this paper takes
Luoyang yituo zhongcheng machinery Co., LTD. as an example to study the layout of the workshop.

Luoyang yituo zhongcheng machinery Co., LTD. Knife shaft production workshop mainly processes agricultural machinery knife shafts and the production of different types of rotary tillers and straw machine knife shafts. The new workshop belongs to the standardized heavy industry production workshop with two-way channels, one outlet in the east and the west, and two openings intersecting the adjacent workshops. This paper mainly takes the processing process of 1GQN200D rotary tiller cutter shaft as the research object to study the material flow and non-material flow of 100 cutter shafts produced in the workshop every day. The production and processing of rotary tiller cutter shafts is a complete process from connecting the pipe of raw materials to the finished cutter shaft. It mainly includes the steps of car connecting pipe, hydraulic and calibration, gap welding and so on, as shown in Fig. 1.
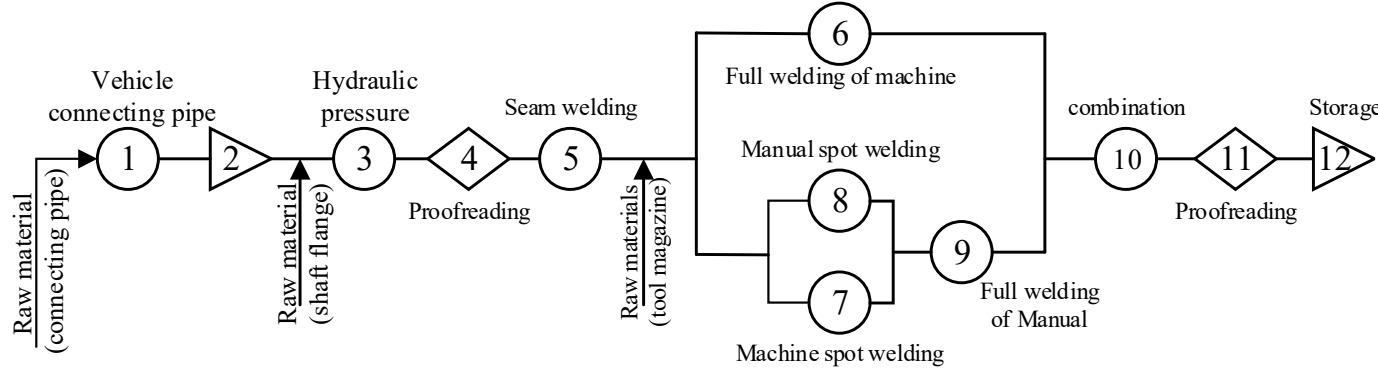

Fig. 1. Flow chart of tool shaft production process

\section{Materials and methods}

Since the 1960s, the initial proposal of SLP theory has provided important data support for the reasonability and clarity of the workshop layout of enterprises. In dealing with the workshop layout problem, the method can accurately use data to combine the logistics and non-logistics analysis and the degree of operation unit closely, so as to calculate the relevant position of each process equipment in the workshop, which greatly improves the production efficiency.

For the layout planning of the whole workshop, the most important is to take product $\mathrm{P}$, output $\mathrm{Q}$, production route $\mathrm{R}$, auxiliary department $\mathrm{S}$ and production time $\mathrm{T}$ as the main factors in the whole production process to carry out planning. As shown in literature [5], the most important thing is to analyze the five basic elements (P, 
Q, R, S, T) of workshop production when the SLP method is used for workshop layout design.

\subsection{Logistics analysis}

According to the technological process of tool and shaft production, the new tool and shaft production unit is divided into 12 unit areas, including Area for Raw material, Lathe area, Hydraulic zone, Proofreading reinforced zone, Gap welding zone, Full welding area of machine, Spot welding area of machine, Spot welding area of Manual, Full welding area of Manual, Area for assembly, Area for proofreading and Storage.

According to the logistics related table theory of American professor--Richard Muther, five symbols A, E,
$\mathrm{I}, \mathrm{O}$ and $\mathrm{U}$ are used to represent the logistics intensity and the proportion of logistics undertaken between each operation unit. Through the quantitative analysis of the logistics from one operation unit to another, the logistic intensity data between operation units are sorted out, and the logistics intensity between operation units is obtained. According to the logistics intensity, the material flow of each operation unit pair is sorted (in descending order), and the logistics grade table is obtained by dividing the operation unit pair by the logistics intensity level according to the logistics intensity level. Then, all the operation units are analyzed to get the logistics correlation diagram of the cutter and shaft processing workshop, as shown in Fig. 2.

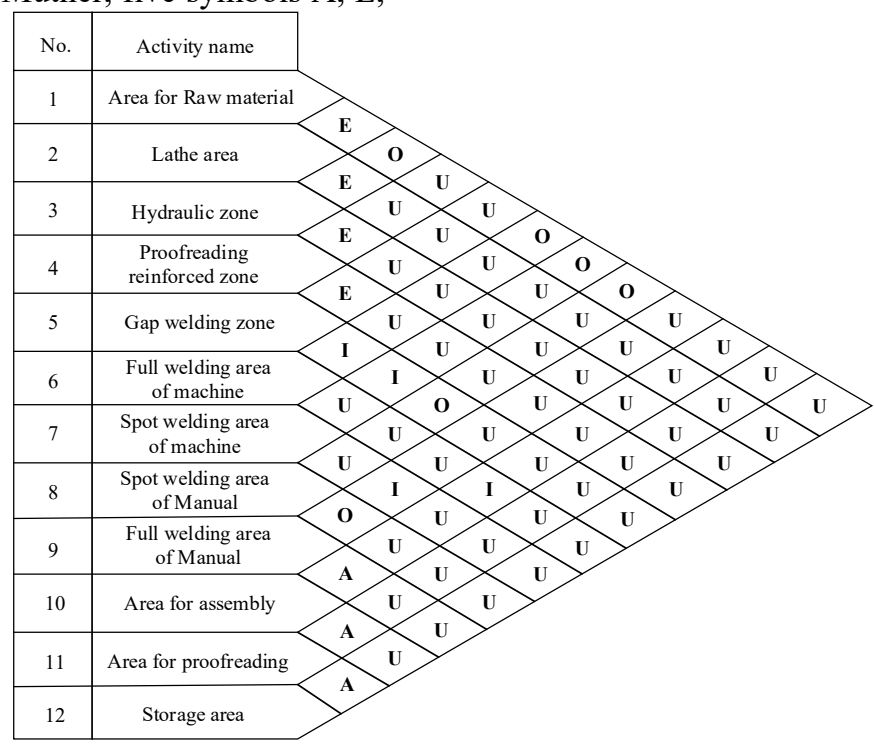

Fig. 2. Logistics related figure

\subsection{Interrelationship analysis of operation units}

The tool and shaft production workshop is a large-scale heavy industry production workshop. The factors influencing the degree of closeness between operating units need to consider the common space of operating units, the similar nature of operating units, the frequency of working contact between operating units, the use of the same public facilities, the convenience of supervision and management, noise, smoke and dust, etc.

According to the relationship level of operation units and the relationship level of operation units in the new tool and shaft production workshop, the non-logistic relationship diagram of each operation unit is drawn, as shown in Fig.3.

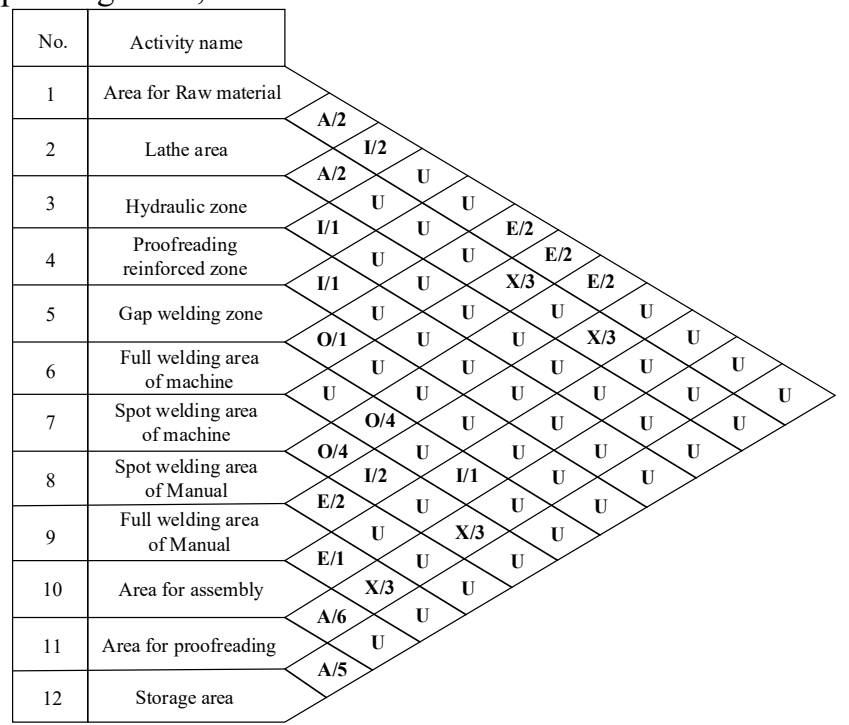

Fig. 3. Non-logistics related figure 
After determining the interrelationship between logistics and non-logistics among each operation unit, the comprehensive interrelationship table between each operation unit shall be constructed. According to the total score of the operation unit in the comprehensive interrelationship table, the total score of the operation unit shall be converted into the relationship density level, and the comprehensive interrelationship diagram of the operation unit shall be constructed, as shown in Fig.4.

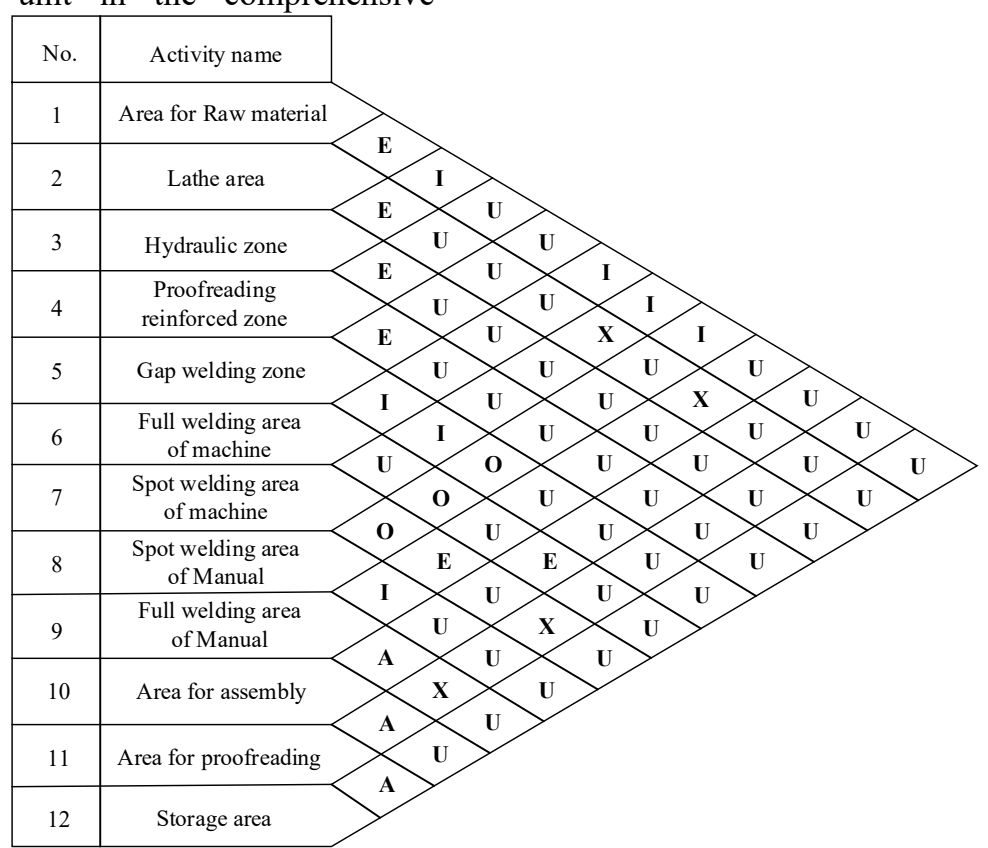

Fig. 4. Unit synthesis interrelationship diagram

According to the interrelationship table, through accurate calculation, the order of the association of the comprehensive interrelationship between each operation unit in the new cutter shaft production workshop is obtained as shown in Table 1.

Table 1. Sort table of comprehensive proximity degree of work units

\begin{tabular}{ccccccccccccc}
\hline No. & $\mathbf{1}$ & $\mathbf{2}$ & $\mathbf{3}$ & $\mathbf{4}$ & $\mathbf{5}$ & $\mathbf{6}$ & $\mathbf{7}$ & $\mathbf{8}$ & $\mathbf{9}$ & $\mathbf{1 0}$ & $\mathbf{1 1}$ & $\mathbf{1 2}$ \\
\hline $\mathbf{1}$ & - & $\mathrm{E} / 3$ & $\mathrm{I} / 2$ & $\mathrm{U} / 0$ & $\mathrm{U} / 0$ & $\mathrm{I} / 2$ & $\mathrm{I} / 2$ & $\mathrm{I} / 2$ & $\mathrm{U} / 0$ & $\mathrm{U} / 0$ & $\mathrm{U} / 0$ & $\mathrm{U} / 0$ \\
$\mathbf{2}$ & $\mathrm{E} / 3$ & - & $\mathrm{E} / 3$ & $\mathrm{U} / 0$ & $\mathrm{U} / 0$ & $\mathrm{U} / 0$ & $\mathrm{X} /-1$ & $\mathrm{U} / 0$ & $\mathrm{X} /-1$ & $\mathrm{U} / 0$ & $\mathrm{U} / 0$ & $\mathrm{U} / 0$ \\
$\mathbf{3}$ & $\mathrm{I} / 2$ & $\mathrm{E} / 3$ & - & $\mathrm{E} / 3$ & $\mathrm{U} / 0$ & $\mathrm{U} / 0$ & $\mathrm{U} / 0$ & $\mathrm{U} / 0$ & $\mathrm{U} / 0$ & $\mathrm{U} / 0$ & $\mathrm{U} / 0$ & $\mathrm{U} / 0$ \\
$\mathbf{4}$ & $\mathrm{U} / 0$ & $\mathrm{U} / 0$ & $\mathrm{E} / 3$ & - & $\mathrm{E} / 3$ & $\mathrm{U} / 0$ & $\mathrm{U} / 0$ & $\mathrm{U} / 0$ & $\mathrm{U} / 0$ & $\mathrm{U} / 0$ & $\mathrm{U} / 0$ & $\mathrm{U} / 0$ \\
$\mathbf{5}$ & $\mathrm{U} / 0$ & $\mathrm{U} / 0$ & $\mathrm{U} / 0$ & $\mathrm{E} / 3$ & - & $\mathrm{I} / 2$ & $\mathrm{I} / 2$ & $\mathrm{O} / 1$ & $\mathrm{U} / 0$ & $\mathrm{U} / 0$ & $\mathrm{U} / 0$ & $\mathrm{U} / 0$ \\
$\mathbf{6}$ & $\mathrm{I} / 2$ & $\mathrm{U} / 0$ & $\mathrm{U} / 0$ & $\mathrm{U} / 0$ & $\mathrm{I} / 2$ & - & $\mathrm{U} / 0$ & $\mathrm{O} / 1$ & $\mathrm{U} / 0$ & $\mathrm{E} / 3$ & $\mathrm{U} / 0$ & $\mathrm{U} / 0$ \\
$\mathbf{7}$ & $\mathrm{I} / 2$ & $\mathrm{X} /-1$ & $\mathrm{U} / 0$ & $\mathrm{U} / 0$ & $\mathrm{I} / 2$ & $\mathrm{U} / 0$ & - & $\mathrm{O} / 1$ & $\mathrm{E} / 3$ & $\mathrm{U} / 0$ & $\mathrm{X} /-1$ & $\mathrm{U} / 0$ \\
$\mathbf{8}$ & $\mathrm{I} / 2$ & $\mathrm{U} / 0$ & $\mathrm{U} / 0$ & $\mathrm{U} / 0$ & $\mathrm{O} / 1$ & $\mathrm{O} / 1$ & $\mathrm{O} / 1$ & - & $\mathrm{I} / 2$ & $\mathrm{U} / 0$ & $\mathrm{U} / 0$ & $\mathrm{U} / 0$ \\
$\mathbf{9}$ & $\mathrm{U} / 0$ & $\mathrm{X} / 1$ & $/ 0$ & $\mathrm{U} / 0$ & $\mathrm{U} / 0$ & $\mathrm{U} / 0$ & $\mathrm{E} / 3$ & $\mathrm{I} / 2$ & - & $\mathrm{A} / 4$ & $\mathrm{X} /-1$ & $\mathrm{U} / 0$ \\
$\mathbf{1 0}$ & $\mathrm{U} / 0$ & $\mathrm{U} / 0$ & $\mathrm{U} / 0$ & $\mathrm{U} / 0$ & $\mathrm{U} / 0$ & $\mathrm{E} / 3$ & $\mathrm{U} / 0$ & $\mathrm{U} / 0$ & $\mathrm{~A} / 4$ & - & $\mathrm{A} / 4$ & $\mathrm{U} / 0$ \\
$\mathbf{1 1}$ & $\mathrm{U} / 0$ & $\mathrm{U} / 0$ & $\mathrm{U} / 0$ & $\mathrm{U} / 0$ & $\mathrm{U} / 0$ & $\mathrm{U} / 0$ & $\mathrm{X} /-1$ & $\mathrm{U} / 0$ & $\mathrm{X} / 1$ & $\mathrm{~A} / 4$ & - & $\mathrm{A} / 4$ \\
$\mathbf{1 2}$ & $\mathrm{U} / 0$ & $\mathrm{U} / 0$ & $\mathrm{U} / 0$ & $\mathrm{U} / 0$ & $\mathrm{U} / 0$ & $\mathrm{U} / 0$ & $\mathrm{U} / 0$ & $\mathrm{U} / 0$ & $\mathrm{U} / 0$ & $\mathrm{U} / 0$ & $\mathrm{~A} / 4$ & - \\
level & $\mathbf{1 1}$ & $\mathbf{4}$ & $\mathbf{8}$ & $\mathbf{6}$ & $\mathbf{8}$ & $\mathbf{8}$ & $\mathbf{6}$ & $\mathbf{7}$ & $\mathbf{7}$ & $\mathbf{1 1}$ & $\mathbf{6}$ & $\mathbf{4}$ \\
sort & $\mathbf{1}$ & $\mathbf{1 1}$ & $\mathbf{3}$ & $\mathbf{8}$ & $\mathbf{4}$ & $\mathbf{5}$ & $\mathbf{9}$ & $\mathbf{6}$ & $\mathbf{7}$ & $\mathbf{2}$ & $\mathbf{1 0}$ & $\mathbf{1 2}$ \\
\hline
\end{tabular}

principle of non-crossing transportation routes, the

\section{Results \& Discussion}

\subsection{Layout principles}

After using the SLP method to analyze the layout of the new tool and shaft machining workshop, combining the principle of green and the principle of single total logistics flow direction, two schemes are proposed for the layout facilities of the new tool and shaft machining workshop, as shown in Fig. 5 and Fig. 6. 


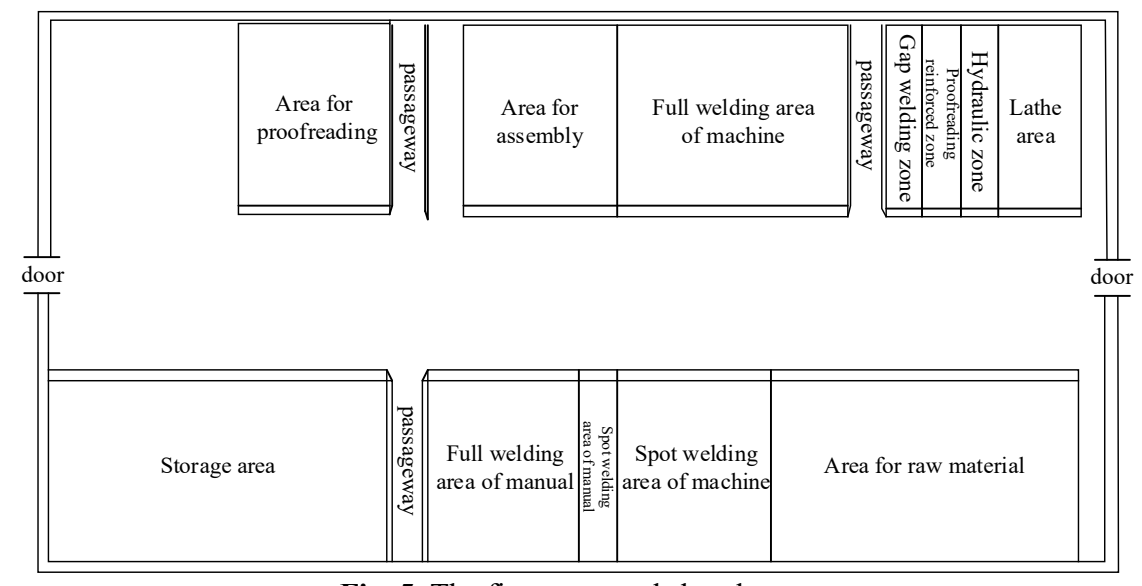

Fig. 5. The first new workshop layout

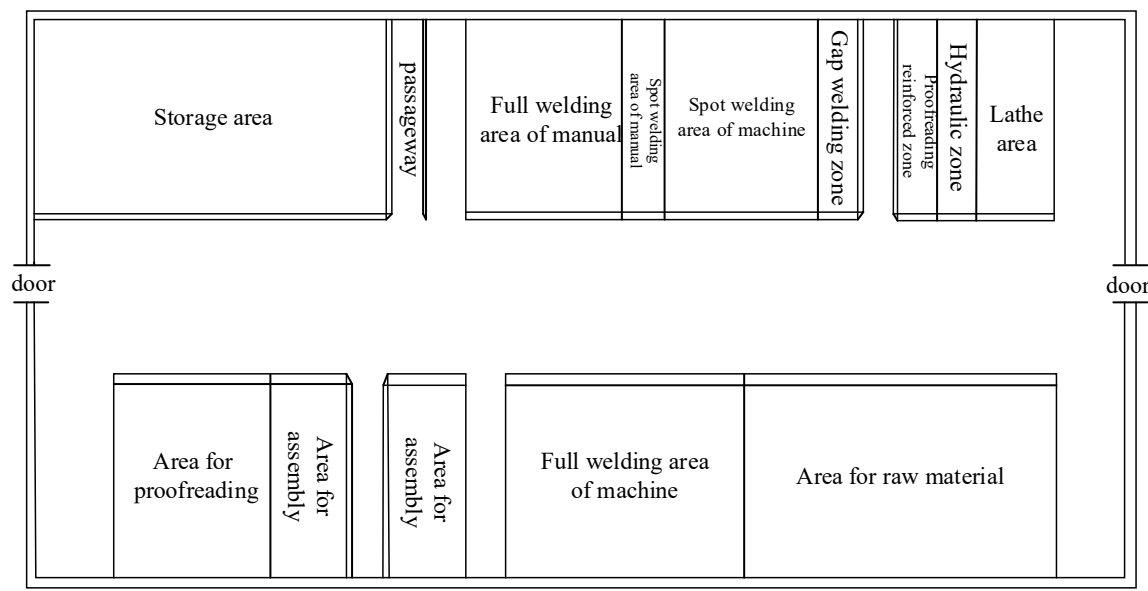

Fig. 6. The second new workshop layout

\subsection{Scheme comparison}

Figure. 5 is designed on the basis of SLP, according to the principle of non-crossing transportation routes of cutter and shaft workshop layout and the principle of single total logistics flow direction, combined with the technological process. It has the advantages of the minimum transportation volume and the best transportation route between each operating unit; However, it also has the disadvantage that the gap welding area is not arranged together with other welding procedures, and it is more complex when controlling the environmental impact of the production process.

Figure 6 is designed on the basis of SLP, mainly according to the green principle of tool and shaft workshop layout, combined with the process flow of tool and shaft production. At the same time, the environmental problems can be better controlled while the transportation volume between each operation unit is small and the transportation route is short.

\section{Conclusions}

In this paper, according to the new tool shaft production workshop for investigation, combined with the SLP method, planning out the minimum material flow, the line of the most scientific workshop facility layout. The SLP method takes into account the non-logistic factors and can satisfy the production mode of knife and shaft order and storage and the humanized management mode. However, the production workshop to transport route requirements are relatively strict, therefore, the layout of facilities in the new workshop must consider more external factors and further improvement.

\section{References}

1. Shijin Liu, Xiaoming Wang, Dongming Yuan, Junwei Zhang. Risks and countermeasures facing China's industrial structure upgrading[J]. Economic Research Reference,2010(13):2-43.

2. Susu Meng. Research on the layout of production workshop facilities based on SLP method[J]. Modern Business Industry, 2018,(30):188-190.

3. Xingang Wang. Research on Layout Optimization of L Workshop Based on SLP Method[D]. Harbin, Northeast Agricultural University, 2017.

4. Jingdong Ge, Binghai Zhou. Workshop layout improvement of company $\mathrm{K}$ based on SLP[J]. Modern Machinery, 2016,(4):1-5.

5. Shoufeng Ji. Modern Facility Planning and Logistics Analysis [M]. Beijing, China Machine Press, 2013. 